\title{
TECHNOLOGICAL AND APPARATUS IMPROVEMENT OF THE PRODUCTION PROCESSES OF BLENDED FRUIT AND BERRY FUNCTIONAL PRODUCTS
}

\section{Andrii Zahorulko ${ }^{1}$ \\ Oleksii Zagorulko²}

DOI: https://doi.org/10.30525/978-9934-588-53-2-54

\begin{abstract}
The main task of the food industry is the full provision of consumer cooperatives with quality food, one of the main sources for the production of which is fruit and berry raw materials. The search for innovative measures to intensify the heat-mass exchange production processes of quality products is needed to solve this problem.

The goal of this work is to justify technological and apparatus improvement of the production processes of functional products on the basis of blended fruit and berry concentrated and dried products. The realization of this goal will allow expanding the range of foodstuff with balanced content of biologically-active substances and other physiologically-functional ingredients.

For the selection of the optimal blending recipe of fruit and berry raw materials into functional products with predicted structural and mechanical properties, such differential function as particle radius distribution, taking into account the average radius, proposed to use. This method allows to determine the impact of the mass fraction of each component on the change of structural and mechanical characteristics of the proposed multicomponent fruit and vegetable purees and pastes.

The technological production process of blended functional fruit and berry concentrated and dried products has been developed, namely apple-based - 50\%; dogwood-based - 40\%; hawthorn-based - 10\%. This technology is different using gentle temperature modes during pre-
\end{abstract}

\footnotetext{
${ }^{1} \mathrm{PhD}$, Associate Professor at the Department of Processes, Devices and Automation of Food Production, Kharkiv State University of Food Technology and Trade, Ukraine

${ }^{2} \mathrm{PhD}$, Associate Professor at theDepartment of Processes, Devices and Automation of Food Production, Kharkiv State University of Food Technology and Trade, Ukraine 
and primary heat treatment, which have been done on the developed and improved equipment (total - 4 units), with the use of radiating flexible film resistive electric heater. Steam blanching and keeping in $\mathrm{NaCl}$ solution processes have been done in a multifunctional all-purpose apparatus. The puree is heated to $30 \ldots .50{ }^{\circ} \mathrm{C}$ by scraper heat exchanger. Concentration processes to dry solids content of $28 \ldots 30 \%$ at a temperature of $50 \ldots 60{ }^{\circ} \mathrm{C}$ for $0.6 \ldots 0.85 \mathrm{~min}$ and further drying at a temperature of $45 \ldots 60{ }^{\circ} \mathrm{C}$ to a moisture of $6 \ldots 8 \%$ DS are implemented in a rotary film apparatus and rolled IR dryer, accordingly.

Changes in color formation have been studied at all stages of production from puree to dried product, which confirmed the quality of semifinished products because color is one of the main factors determining the physicochemical changes of raw materials and may influence consumer choice. The brightness and purity of the experimental samples have been compared, and it has been found that the loss of brightness has a small percentage, within $3 . . .8 \%$, and the purity of color has been reduced to half, which has been explained by mass losses of fruit and berry raw materials during heat-mass exchange treatment. In general, an attractive visual color of the products is provided.

The line for production of blended functional fruit and berry concentrated and dried product using the developed equipment was chosen. The line can be located in places of growth of fruit and berry raw materials, which will significantly reduce the costs of transportation, storage of raw materials and ensure its resource efficiency.

\section{Introduction}

The main task of food industry is the full provision of consumer cooperatives with quality food, one of the main sources for the production of which is fruit and berry raw materials. In addition, there is the increased demand for high quality natural products. The search for innovative measures to intensify the heat-mass exchange production processes of quality products is needed to solve this problem [1].

Most of the existing technological and apparatus solutions are focused on large volumes of raw material processing and are located in giant industries, creating the need for storage and transportation of processed raw materials. At the same time, most of the heat-mass exchange equipment is obsolete 
and has lost its repair ability. For the operation of heating equipment, steam generators are usually still used, which makes it difficult to stabilize the temperature effects on raw materials. This artificially increases the metal consumption of the entire line with the complexity of operation [2, p. 78].

Projecting of mobile lines for the processing of fruit and berry raw materials directly in the places of its growth will reduce transport costs, simplify the operating conditions and increase the competitiveness of such enterprises. Implementation of such mini-lines requires the development and improvement of heat-mass exchange equipment based on resourceefficient heaters and the creation of appropriate conditions for the production of high-quality multifunctional blended fruit and berry products [3, p. 50].

This approach solves the issues and causes the need to modernize the existing technological equipment to create conditions for the development of small farmers' businesses [4, p. 16].

The goal of this work is to justify technological and apparatus improvement of the production processes of functional products on the basis of blended fruit and berry concentrated and dried products for their further use as a separate link of healthy nutrition and as natural fillers in various food and treatment and preventive care products. The realization of this goal will allow to expand the range of foodstuff with balanced content of biologically-active substances (BAS) and other physiologically-functional ingredients (PFI) [5, p. 333].

To achieve this goal and its practical implementation, the following tasks were solved:

- to propose methods to create a recipe of blended fruit and berry semifinished products to obtain on their basis various functional products with predicted structurally-mechanical properties;

- to develop the basic diagram of production of blended fruit and berry concentrated and dried products;

- to present the constructions of improved heat-mass exchange apparatus for the realization of the production of blended functional products;

- to confirm the effectiveness of the introduction of production mode parameters using the proposed equipment by determining the color change of raw materials;

- to propose the technical and apparatus scheme of the line for production of blended fruit and berry concentrated and dried products. 


\section{Justification of recipe of blended functional fruit and berry products}

The prospect of using natural raw materials is due to the high content of BAS, PFI and other useful substances for humanity. However, it should be borne in mind that each fruit and berry raw material has certain properties that must be taken into account when consumed and sometimes even monitor its consumption. In the context of rational natural nutrition, it is necessary to create functional concentrated and dried products with optimal recipe ratio (BAS and PFI). Determining the urgency of the introduction of blending methods of fruit and berry raw materials in multicomponent products with predicted structurallymechanical properties [6, p. 268].

To solve the problem of proposing the method of blending of fruit and berry raw materials into functional products with predicted structural and mechanical properties, we used such differential function as particle radius distribution (DFD), taking into account the average radius $\left(r_{\text {avg. }}\right)$. The presences of its own DFD in each component of the fruit and berry raw material with the relevant $r_{\max }$ allows study and compare the obtained dispersion and resistance by determining the surface interaction of the selected recipe components with each other. An accurate determination of the interaction of fruit and berry components on the resistance of the selected composition and a clear understanding of changes in the obtained structure of the food mass are provided [7, p. 2].

During the research of the proposed method, fruit and berry raw materials have been used, followed by blending. The main raw material is apple, with the addition of other components that can change the organoleptic, treatment and preventive care properties with natural colorants. In the Table 1 the recipe ratio of the blended composition is given.

The description of the obtained isotherms constructed by the Van Bamelen tensometric method has been carried out by the equation:

$$
u=u_{0} \exp \left(-\frac{a_{293} \operatorname{In}(r)+b_{293}}{r}\right)
$$

where $\mathrm{u}$ is the current moisture of the experimental sample, per unit; $\mathrm{u}_{0}$ is hygroscopic moisture by sorption, per unit;

$r$ is the current radius of the capillaries of the experimental sample, $n m$; 
$\alpha_{293} ; b_{293}$ - steels, given based on the type of the experimental sorptiondesorption isotherms and $\mathrm{T}=293 \mathrm{~K}$.

Table 1

\section{Blended ratio of fruit and berry compositions}

\begin{tabular}{|c|c|c|c|}
\hline Component composition & a & b & c \\
\hline Apple & 60 & 70 & 50 \\
\hline Dogwood & 30 & 20 & 40 \\
\hline Hawthorn & 10 & 10 & 10 \\
\hline \multicolumn{3}{|c|}{ Control sample - apple raw material (100\%) } \\
\hline
\end{tabular}

It should be noted that the proposed method is simplified, since steels $\alpha$ and $b$, equation 1 , are included in the analytic expression that describes the DFD.

$$
f(r)=\frac{b_{293}-a_{293}+a_{293} \ln (r)}{r^{2}} \exp \left(-\frac{a_{293} \ln (r)+b_{293}}{r}\right)
$$

It makes it easy to find equilibrium values of the sorption-desorption in a wide range of hygroscopic moisture content, increasing the accuracy of the obtained values of $a, b$.

Determination of the average radius of the porous structure of the product $\bar{r}$ in terms of the recipe ratio of the blended composition has been carried out by the equation:

$$
\bar{r}=\int_{r_{\min }}^{r_{\operatorname{man}}} r f(r) d r
$$

where $r_{\min }$ is the minimum radius of the micro capillaries of the blended mass;

$\mathrm{r}_{\max }$ is the maximum radius of the micro capillaries of the blended mass.

As a result of studies of the obtained curved lines of the distribution of particles by radius (DFD) for the compositions listed in table 1, are shown in Figure 1.

The average radius of the micro capillaries is determined by analytical expression (2) taking into account $f(r)$ that is for the compositions: $\mathrm{a}-\bar{r}=2.38 \mathrm{~nm}, \mathrm{~b}-\bar{r}=2.06 \mathrm{~nm}, \mathrm{c}-\bar{r}=1.80 \mathrm{~nm}$. There is a tendency to reduce the dispersion in the transition from the content of the dogwood $20 \%$ (sample b) to the content of $30 \%$ (sample a), and growth with increasing the content of dogwood to $40 \%$ in (sample c). At the same 


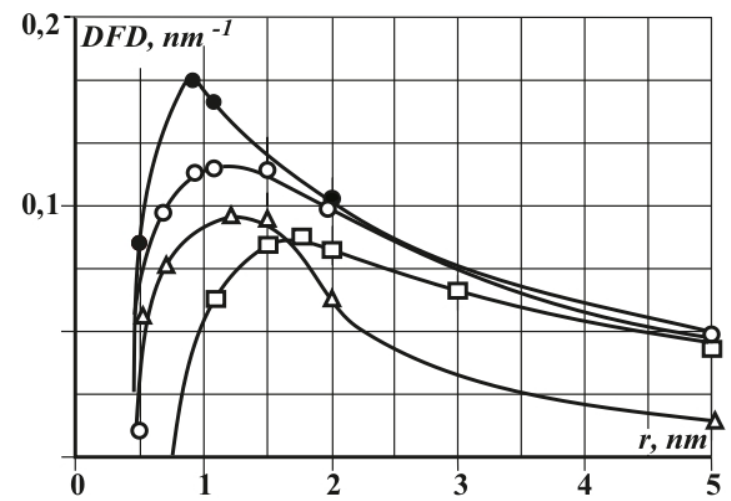

Figure 1. Differential function of distribution of particles by radius in blended ratio of fruit and berry compositions:

(a) $60 \%$ apple, $30 \%$ dogwood, $10 \%$ hawthorn; (b) $70 \%$ apple, $20 \%$ dogwood, $10 \%$ hawthorn; (c) $50 \%$ apple, $40 \%$ dogwood, $10 \%$ hawthorn; control (100\% apple raw material)

significant strengthening of the structure in the sample c $(40 \%$ of the dogwood), compared with 20 and $30 \%$ of its introduction and control is provided. This result confirms the up-to-date using of the proposed method of blending of fruit and berry raw materials into functional products with predicted structurally-mechanical properties. This necessitates further feasibility studies for the technological and apparatus production processes of blended fruit and berry functional concentrated and dried products. Since natural raw materials have a limited expiration date after harvesting, the maximum preservation of their initial properties at all stages of production is required.

\section{Technological production process of blended functional fruit and berry concentrated and dried products}

Taking into account the limited period of processing of vegetable raw materials requires a reasoned technological and apparatus improvement of the production processes of blended functional fruit and berry concentrated and dried products, including the basic technological operations necessary to ensure their high quality production. 
The basic technological production process of blended functional fruit and berry concentrated and dried products is shown in Figure 2.

Blended ratio of fruit and berry compositions has been previously proposed in the Table 1 . The harvested ripe fruit and berry raw material goes to the washing machine, after which it is inspected and cut if necessary (apple).

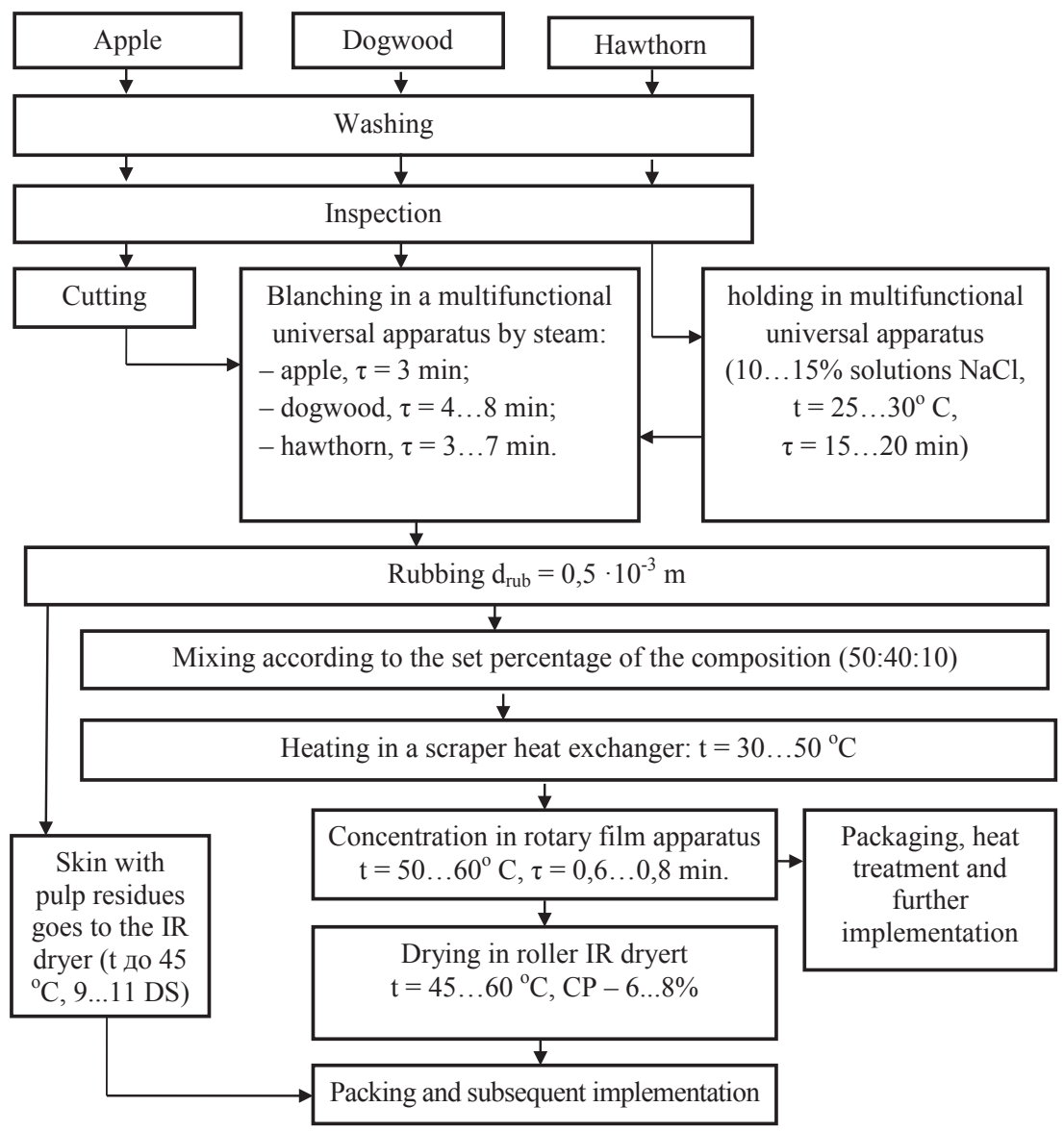

Figure 2. Basic diagram of the production of blended functional fruit and berry concentrated and dried products 
Then it comes to blanching in a multifunctional universal machine (or apparatus) with steam (apple, $\tau=3 \mathrm{~min}$; hawthorn, $\tau=4 \ldots 8 \mathrm{~min}$; dogwood, $\tau=3 \ldots 7 \mathrm{~min}$ ). The dogwood is additionally kept in a universal multifunctional apparatus $\left(10 \ldots 15 \% \mathrm{NaCl}\right.$ solution, $\mathrm{t}=25 \ldots 30{ }^{\circ} \mathrm{C}$, $\tau=15 \ldots 20 \mathrm{~min})$. Then the fruit and berry raw material is rubbed till a homogeneous mass $\left(\mathrm{d}_{\mathrm{rub}}=0.5 \cdot 10^{-3} \mathrm{~m}\right)$ with separation of skins and stones. Obtained after rubbing skin with pulp residues immediately goes to the IR dryer, where it is dried at a temperature of not more than $45^{\circ} \mathrm{C}$, to a final moisture content of $9 \ldots 11 \%$ of dry solids (DS). After that, it is sent for sale in various industries, in particular for extraction.

Further, the obtained homogeneous puree is blended in a ratio of: apple-dogwood - hawthorn: 50:40:10 till a homogeneous consistency. The obtained blended puree food mass is sent to the scraper heat exchanger and get heated up to $30 . .50^{\circ} \mathrm{C}$, the heating of which is done by a radiating flexible film resistive electric heater (RFFREH) [8, p. 2]. Then the heated mass is sent into a rotary film apparatus (RFA) with an advanced heating system for concentration to dry solids of $28 \ldots 30 \%$ at a temperature of $50 \ldots 60{ }^{\circ} \mathrm{C}$ for $0.6 \ldots 0.85$ minutes. After that, the concentrated paste, if necessary, is sent to the packing machine with a further filling in the container, or is sent from the RFA for drying in a roller IR dryer, where it is dried at a temperature of $45 \ldots 60{ }^{\circ} \mathrm{C}$ to a moisture of $6 \ldots 8 \%$ of DS with further packing in light-proof sealed container of different volumes and sold in retail networks.

The majority of technological operations in the production of blended functional fruit and berry concentrated and dried products are done on advanced heat-mass exchange equipment under conditions of clear stabilization temperature [9, p. 152].

\section{Improvement of heat-mass exchange equipment for production of blended functional products}

The analysis of the scheme of production of blended functional fruit and berry concentrated and dried products allowed distinguishing the basic heat-exchange operations, which greatly influence the quality of the products obtained. These include: preheating of the raw material, steam blanching and keeping, concentrating and drying. In most cases, mechanization is characterized by the complexity of the stabilizing impact, as heating shells are used, which complicates the precise control: steam 
pressure - temperature. It requires steam generators and piping networks, increases metal consumption, energy costs for technological processes, causes complexity of operation.

One way to solve these structural and technological disadvantages is to replace the heating system with intermediate coolants with a stabilized electrical. This will ensure an equal distribution of heat flow, eliminate heating shells and their piping networks, and simplify equipment operation.

The first heat treatment of vegetable raw materials in the proposed method is steam blanching and keeping in a multifunctional universal apparatus (MUA, Figure 3).

Which consists of the reservoir 1 mounted on the moving platform 2 for mobility. At the bottom of the reservoir 1 there is the perforated dispenser 3 , which is connected to the technical pipe of the protecting steam line 4 . Also the reservoir 1 is equipped with the tap for draining of process fluids 5 .

The moving platform 2 of the MUA allowed accommodating the engine compartment 6 on the basis of a worm reduction gearbox. To which, by means of the coupling 7 , the rotor shaft 8 with the replaceable sectionmodular perforated liner 9 is attached. Also, the platform 2 has the steam generator compartment 10 , the vacuum compartment 11 with the vacuum pipeline 12 and the draw-out rail with rotary lifting mechanism 13 .

To the reservoir 1, with the help of ringbolts 14 (4 pcs.), the cover of working technological reservoir 15 is attached having a rubber seal 16 in places of interaction with the reservoir. The on-off valves 17 is on the cover of working technological reservoir 1.

The next heat-exchange operation is preheating, which we propose to perform on the advanced scraper heater. The vertical scraper heater (Figure 4) has a vertical working chamber 1, the heating of which is done by RFFREH 2 with the insulating surface.

Chopped food mass goes through the pipe 3 , where it is on the distributing disk 4 forming a uniform layer of raw material and placed on a rotary rotor 5. Then the raw material is picked up with the hinged blades 6 and is moved on the working surface 7 . The duration of heat treatment is regulated with the thickness of the raw material layer and the speed of rotation of the blades driven with the motor 8 . The discharge of raw material is done through the pipe 9. Then the heated mashed mass goes to the concentration into an advanced rotary film apparatus (Figure 5). 


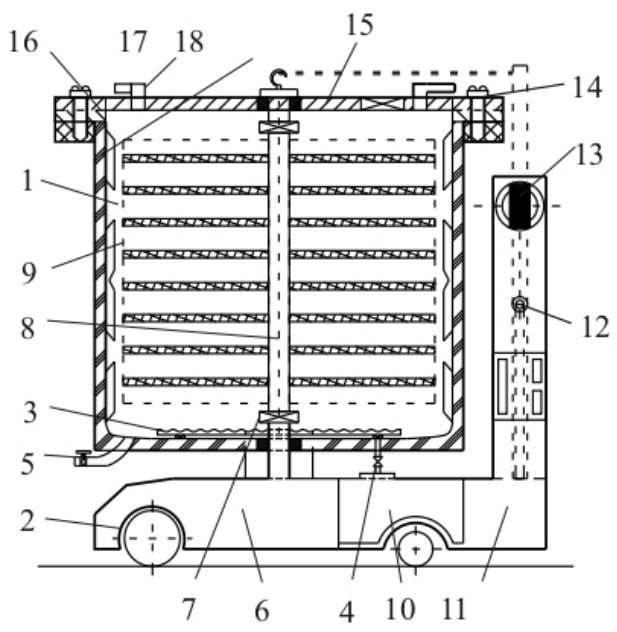

Figure 3. Diagram of multifunctional universal apparatus:

1 - a reservoir; 2 - a moving platform; 3 - a perforated dispenser; 4 - a pipe of the protecting steam line; 5 - a tap for draining of process fluids; 6 - an engine compartment;

7 - a coupling; 8 - a rotor shaft; 9 - a replaceable section-modular perforated liner;

10 - a steam generator compartment; 11 - a vacuum compartment; 12 - a vacuum pipeline; 13 - a draw-out rail with rotary lifting mechanism; 14 - ringbolts; 15 - a cover of working technological reservoir; 16 - rubber seal; 17 - on-off valves; 18 - a radiating

flexible film resistive electric heater with insulating surface (RFFREH)

The rotary film apparatus has the working chamber 1 , which is heated with the radiating flexible film resistive electric heater 2 with insulating surface. The pumping and discharging of the raw material is done through the pipes 3 and 4, and the discharge of the secondary steam with the pipe 5, after its prior accumulation in the separation space 6 . The formation of the desired raw material layer is provided with the distribution ring 10 mounted at the top of the rotor 8 , which rotates from the motor 7 and on which the hinged blades 9 are fixed.

After concentration, the paste-like blended mixture is sent to the last heatexchange treatment, namely drying in the IR field, which is implemented on the rolled IR dryer (Figure 6).

The drying process is done as follows: puree with a content of $26 \ldots 30 \%$ of DS after concentration is pumped with the screw with a separating 


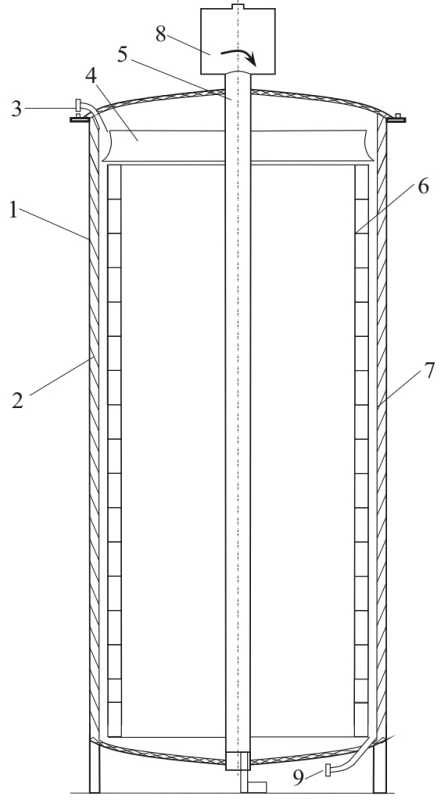

Figure 4. Advanced model of vertical scraper heater:

1 - a vertical working chamber; 2 -radiating flexible film resistive electric heater with insulating surface (RFFREH); 3 - a pipe for raw materials pumping; 4 -a distributing disk; 5 - a rotary rotor; 6 - hinged blades; 7 -a working surface; 8 - an electric motor with worm reduction gearbox; 9 - a pipe for raw materials discharge.

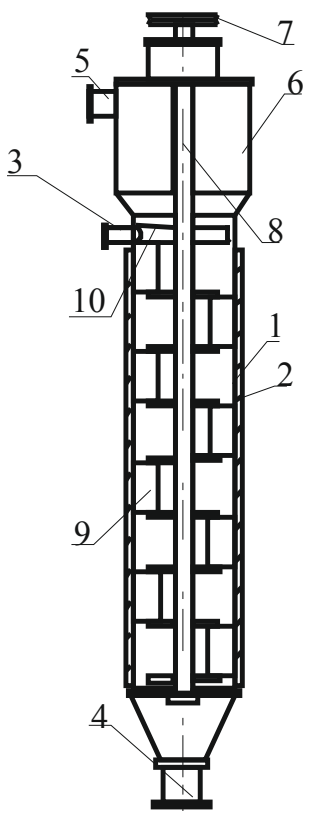

Figure 5. Advanced rotary film apparatus:

1 - a working chamber; 2 - a radiating flexible film resistive electric heater with insulating surface (RFFREH); 3, 4 -pipes for pumping and discharging of raw materials; 5 - a secondary steam discharge pipe; 6 - a separation space; 7 an electric motor; 8 - a rotor; 9 - a hinged blade; $10-$ a distribution ring

nozzle 4 on the working grooved drum 2 forming the necessary layer of raw material for drying. When rotating the drum counterclockwise, intensive drying of the raw material at the required temperature is done. The intensification of the process is provided by the creation of forced convection with the injection fan 6 . And the discharge of secondary air is provided by the pipe 7 . The dried raw material is cut with knives 6 and falls into the product bin. 


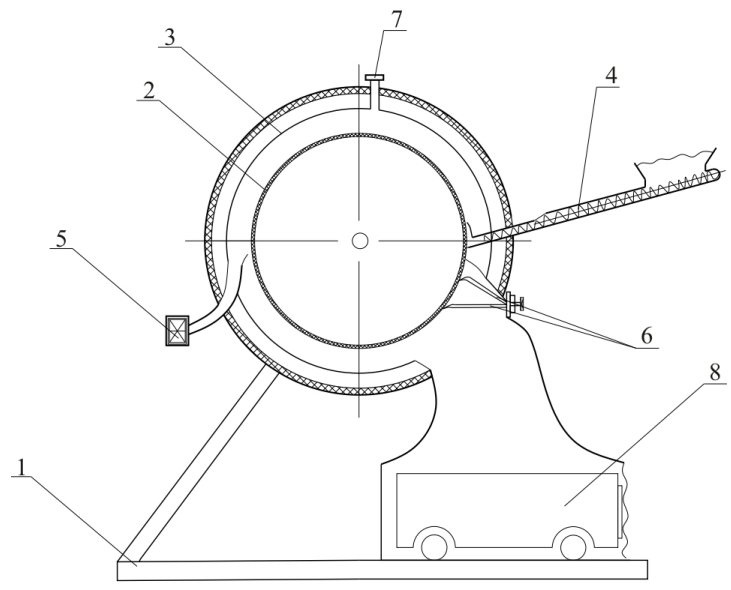

Figure 6. Rolled IR drier:

1 - racks; 2 - a working grooved drum; 3 - a radiating flexible film resistive electric heater with insulating surface (RFFREH); 4 - an injection screw with a separating nozzle; 5 - an injection fan; 6 - cutting knives; 7 steam discharge pipe; 8 - a product bin

\section{Research of change in the quality of blended functional fruit and berry products}

Having considered the basic technological diagram of production of blended functional fruit and berry products and the proposed advanced heat-exchange equipment it is necessary to prove the quality of the obtained products. Namely, the changes of color formation at all stages of production from puree to dried product were studied. Because color is one of the main factors characterizing the physical and chemical changes of natural raw materials and is fundamental for the consumer.

The first stage of the research was to determine the color characteristics of each of the components and blended compositions according to the recipe ratio (Table 1), the results of the studies are given in Table 2.

The dominant wavelength in the paste sample a is $613.3 \mathrm{~nm}$ and characterized with red-orange colour with the purity of colour tone $-73.6 \%$. For samples b and c -615.8 and $619.8 \mathrm{~nm}$, accordingly. For sample b, the purity of colour tone $(76.2 \%)$ corresponds to red-orange. The purity of tone of $79.1 \%$ in sample c characterizes the red-orange colour. 
Table 2

Colour characteristics of experimental samples of components and blended fruit and berry puree compositions

\begin{tabular}{|c|c|c|c|c|}
\hline \multirow{2}{*}{$\begin{array}{c}\text { Experimental } \\
\text { samples }\end{array}$} & $\begin{array}{c}\text { Dominant } \\
\text { wavelength }\end{array}$ & Brightness & Colour purity & \multirow{2}{*}{$\begin{array}{c}\text { Visual } \\
\text { characteristic } \\
\text { of sample color }\end{array}$} \\
\hline & $\lambda \mathrm{nm}$ & $T, \%$ & $\mathrm{P}, \%$ & \\
\hline Apple & 560.2 & 20.5 & 64.5 & greenish-yellow \\
\hline Dogwood & 608.1 & 38.2 & 77.8 & bright-red \\
\hline Hawthorn & 590 & 33.5 & 90.4 & dark-orange \\
\hline Sample a & 613.3 & 35.9 & 73.6 & red-orange \\
\hline Sample b & 615.8 & 33.5 & 76.2 & red-orange \\
\hline Sample c & 619.8 & 38.6 & 79.1 & red-orange \\
\hline
\end{tabular}

The second stage of the study determined the colour change of blended puree after concentration in accordance with the regimes specified in the basic diagram (Figure 2) in the proposed advanced rotary film apparatus (Table 3).

Table 3

Color characteristics of experimental samples of blended fruit and berry paste compositions

\begin{tabular}{|c|c|c|c|c|}
\hline $\begin{array}{c}\text { Samples of } \\
\text { fruit and } \\
\text { berry paste } \\
\text { compositions }\end{array}$ & $\begin{array}{c}\text { Dominant } \\
\text { wavelength }\end{array}$ & Brightness & Colour purity & $\begin{array}{c}\text { Visual } \\
\text { characteristic } \\
\text { of sample color }\end{array}$ \\
\hline Sample a & 609.2 & $\mathbf{T n}, \boldsymbol{\%}$ & $\mathbf{P , \%}$ & light red-orange \\
\hline Sample b & 612.6 & 35.3 & 76.5 & light red-orange \\
\hline Sample c & 615.3 & 36.3 & 79.1 & red-orange \\
\hline
\end{tabular}

The dominant wavelength in the paste sample a is $609.2 \mathrm{~nm}$ and corresponds to a light red-orange colour with the purity of $76.5 \%$. For pastes b and c, 612.6 and $615.3 \mathrm{~nm}$, accordingly. For sample b, the purity of tone $(65.3 \%)$ corresponds to light red-orange colour. The sample $\mathrm{c}$ is characterized by a red-orange colour as it has the purity of tone at the level of $79.1 \%$.

The third stage of the study was to determine the colour change in dried blended functional products (Table 4). 
Table 4

\section{Colour characteristics of experimental samples of dried functional fruit and berry products}

\begin{tabular}{|c|c|c|c|c|}
\hline \multirow{2}{*}{$\begin{array}{c}\text { Samples of dried } \\
\text { products }\end{array}$} & $\begin{array}{c}\text { Dominant } \\
\text { wavelength }\end{array}$ & Brightness & $\begin{array}{c}\text { Colour } \\
\text { purity }\end{array}$ & $\begin{array}{c}\text { Visual evaluation } \\
\text { of sample color }\end{array}$ \\
\cline { 2 - 4 } & $\lambda \mathbf{n m}$ & $\mathbf{T , ~ \%}$ & $\mathbf{P}, \boldsymbol{\%}$ & \\
\hline Sample a & 526.9 & 31.2 & 35.2 & blue-red \\
\hline Sample b & 623.8 & 31.9 & 35.6 & red-orange \\
\hline Sample c & 568.5 & 32.6 & 35.3 & bluish-orange \\
\hline
\end{tabular}

The characteristic wavelength of dried functional fruit and berry products for sample a is $526.9 \mathrm{~nm}$ and corresponds to a blue-red colour with the purity of tone of $35.2 \%$. Samples b and c have lengths of 623.8 and $568.5 \mathrm{~nm}$, accordingly. For sample $b$, the purity of tone of $35.6 \%$ corresponds to redorange colour. The sample $\mathrm{c}$ is characterized by a bluish-orange colour, as it has the purity of tone at the level of $35.3 \%$.

Having analyzed the obtained colour changes (Table 2-4) and compared the brightness and purity of the tone of the samples, it is possible to conclude that the loss of brightness has a small percentage, within $3 \ldots 8 \%$. The purity of the colour is halved, which is explained by the drying of the mass of fruit and berry raw materials during heat-mass exchange treatment. Although, an attractive visual colour of the obtained products is provided for the consumer.

\section{Technical and apparatus diagram of the production line}

for blended functional fruit and berry concentrated and dried products

To detail the technological and apparatus production process of blended functional fruit and berry products, we present its technical and apparatus diagram of the line (Figure 7).

The proposed production line for blended functional fruit and berry concentrated and dried products may be located in areas of growth of fruit and berry raw materials. It is characterized by: mobility, simplicity, resource efficiency.

\section{Conclusions}

The relevance of using of such differential function as particle radius distribution, taking into account the average radius to choose the optimal 


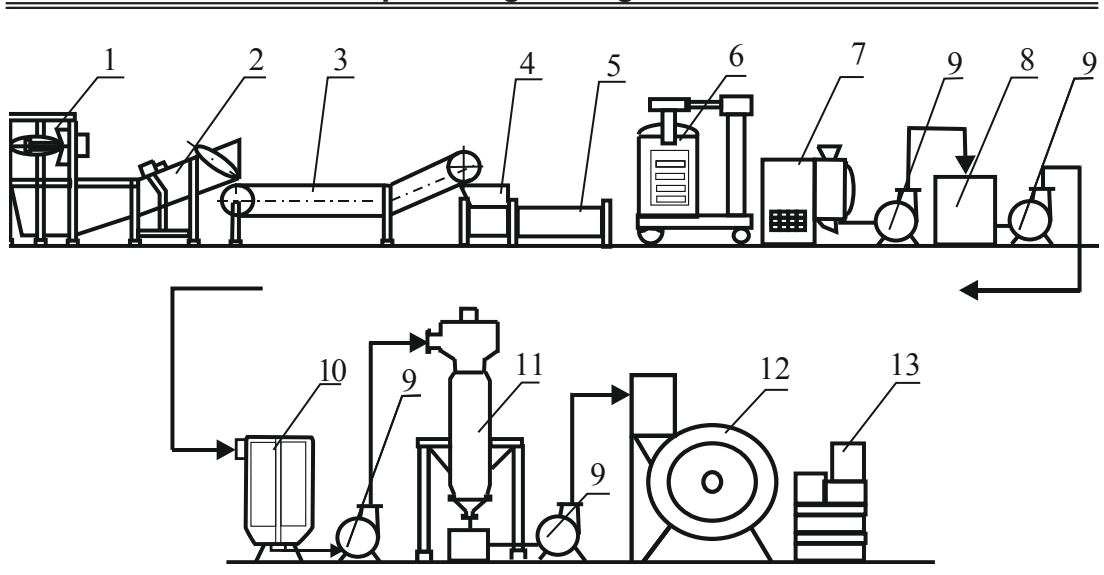

Figure 7. Technical and apparatus diagram of the production line for blended functional fruit and berry concentrated and dried products:

1 - a container tilter; 2 - a conveyor machine for washing; 3 - an inspection roller conveyor; 4 - a machine for cutting fruit and berry raw materials; 5 - a container for accumulation of liners; 6 - a multifunctional universal apparatus; 7 - a wiping machine; 8 - a collector-measure; 9 - a gear pump; 10 - a scraper heat exchanger;

11 - a rotary film apparatus; 12 - a rolled IR dryer; 13 - a packing machine

recipe for blending fruit and berry raw materials into functional products with the predicted structurally-mechanical properties. The average radius of the micro capillaries have been determined taking into account $f(r)$, they are for the compositions: $\mathrm{a}-\bar{r}=2.38 \mathrm{~nm}, \mathrm{~b}-\bar{r}=2.06 \mathrm{~nm}, \mathrm{c}-\bar{r}=$ $1.80 \mathrm{~nm}$, which indicates a significant strengthening of the structure of the sample c with a content of dogwood $40 \%$.

The technological production process of blended functional fruit and berry concentrated and dried products has been developed, namely applebased - 50\%; dogwood-based - 40\%; hawthorn-based - 10\%. The developed technology is different by using of gentle temperature modes during the preliminary and basic heat treatment, which were done on the developed and improved equipment (total -4 units) with the use of the radiating flexible film resistive electric heater (RFFREH). Steam blanching and keeping processes in $\mathrm{NaCl}$ solutions have been done in the multifunctional all-purpose apparatus. The purée is heated to $30 \ldots 50{ }^{\circ} \mathrm{C}$ by scraper heat exchanger. Concentration processes to dry solids content of $28 \ldots 30 \%$ at a temperature of $50 \ldots 60{ }^{\circ} \mathrm{C}$ for 
$0.6 \ldots 0.85 \mathrm{~min}$ and further drying at a temperature of $45 \ldots 60{ }^{\circ} \mathrm{C}$ to a moisture of $6 \ldots 8 \%$ DS are implemented in a rotary film apparatus and rolled IR dryer, accordingly. Studies of the color changes at all stages of production from puree to dried products confirm the preservation of the quality of semi-finished products. Since the change in brightness and purity of the experimental samples had a small percentage, within $3 \ldots 8 \%$, and the purity of color has been reduced to half, which has been explained by mass losses of fruit and berry raw materials during heat-mass exchange treatment.

The complete line has been chosen for production of blended functional fruit and berry concentrated and dried products using the developed equipment. The line can be located in places of growth of fruit and berry raw materials, which will significantly reduce the costs of transportation, storage of raw materials and ensure resource efficiency..

\section{References:}

1. Ahrobiznes sohodni / Vyrobnytstvo orhanichnoi silhospproduktsii ta syrovyny. URL: http://agro-business.com.ua/agro/u-pravovomu-poli/item/11002-vyrobnytstvo-orhanichnoi-produktsii-pravyla-i-normy.html

2. Alabina, N. M., Drozdova, V. I., Volodzko, G. V. i dr. (2006). Plodoovoshhnye konservy profilakticheskogo naznacheniya. Pishhevaya promyshlennost, no. 11, pp. 78-79.

3. Shazzo, R. I., \& Ovcharova, H. P. (2005). Produkty detskoho pitaniia iz rastitel'noho i miasnoho syr'ia infrakrasnoi sushki. Khranenie i pererabotka sel'khozsyr'ia, no. 1, pp. 50-52.

4. Pilipenko, O. Ye. (2017). Rozvitok harchovoyi promislovosti Ukrayini. Nacionalnij universitet harchovih tehnologij. Naukovi praci NUHT, T. 23, no. 3, pp. 15-25.

5. Antipov, S. T., \& Zhashkov, A. A. (2010). Sovremennye tekhnologii pri poluchenii plodovo-yagodnykh poroshkov [Modern technologies in the production of fruit and berry powders], vol. 16, no. 2, pp. 332-336.

6. Lian Huang, $\mathrm{Li} \mathrm{Ba}$, Xiaoyi Zhang, Shunlong Gong. Re-understanding the antecedents of functional foods purchase: Mediating effect of purchase attitude and moderating effect of food neophobia. Food Quality and Preference, vol. 73, April 2019, pp. 266-275.

7. Cherevko A. I., Kiptela L. V., Zaharenko V. A., \& Zagorulko A. N.; assignee: Kharkiv State University of Food Technology and Trade (10.10.2013). Method of determining the strength of the multicomponent structure of plant pastes. Patent UA $83943 \mathrm{U}$, MPK G01N 30/00, A23L 1/06. Appl. № u201302710. Filed 04.03.2013. Bull. № 19. 4.

8. Zagorulko, A. M., \& Zagorulko, O. Ye.; assignee: Kharkiv State University of Food Technology and Trade. (24.06.2016). Hnuchkyi plivkovyi rezystyvnyi elektronahrivach vyprominiuiuchoho typu. Patent UA 108041 U, MPK G05D 23/19, B01D 1/22, H05B 3/36. Appl. № u201600827. Filed 02.02.2016. Bull. № 12, 4.

9. Vanshin, V., \& Vanshina, E. (2012). Tekhnologiya pishchekontsentratnogo proizvodstva: uchebnoe posobie. Orenburg: OGU, 180 p. 